\title{
College English Classroom Teaching Evaluation Based on Particle Swarm Optimization - Extreme Learning Machine Model
}

\author{
https://doi.org/10.3991/ijet.v12i05.6782 \\ Baojian Wang \\ Northwest A\&F University, Yangling, Shaanxi, China \\ wang.baojian@163.com \\ Jing Wang* \\ Northwest A\&F University, Yangling, Shaanxi, China \\ jingwangenwsuaf.edu.cn \\ Guoqiang $\mathrm{Hu}$ \\ Northwest A\&F University, Yangling, Shaanxi, China \\ hgqenwsuaf.edu.cn
}

\begin{abstract}
The quality evaluation of English classroom teaching carries great significance in promoting English teaching reform and raising the quality of English education at university level in China. In this paper, a quality evaluation index system is introduced for the classroom teaching of English as a foreign language (Extreme Learning Machine), and an EFL classroom teaching quality evaluation model is built based on the Particle Swarm Optimization (PSO) - Extreme Learning Machine (ELM) algorithm with an ELM model constructed for comparison. A comparison shows that the PSO-ELM algorithm can obtain better accuracy with less hidden layer neurons, hence lowering the demand upon experiment samples and strengthening the fitting ability of the model. Experiment results show that the PSO-ELM algorithm is feasible to evaluate classroom teaching of English as a foreign language. The designed English classroom teaching quality evaluation index system is thus confirmed as effective, and is expected to improve the quality and management of classroom teaching of English as a foreign language.
\end{abstract}

Keywords-PSO-ELM model, classroom teaching evaluation, college English teaching

\section{Introduction}

College English classroom teaching evaluation refers to making value judgments upon the realization of classroom teaching effects and goals of college English teachers with scientific evaluation technologies, means and methods according to the teaching rules, principles, and goals [1]. The evaluation serves as an important means 
for college English teaching quality management. Therefore, constructing a scientific, feasible and effective teaching quality evaluation system for the classroom teaching of English as a foreign language (EFL) in China at university level carries great significance and is even imperative in improving classroom teaching and reinforcing teacher management.

To realize such an ideal evaluation system, it is necessary to review the prior researches. The existed researches mainly focus on three aspects. The first aspect regards the evaluation subject. In literature [2], Cui Huiyong and Feng Xiuru construct a teacher self-evaluation mechanism which can promote the development of vocational English teachers. In literature [3], Wu Yian and Tang Jinlan study the influence of a self-evaluation system with an integrated English writing teaching experiment for college English teachers. In literature [4], Shi Qiaoyun evaluates the behaviors of college English classroom teachers. Literature [5] reflects on the English teacher evaluation system currently being used in high schools. Literature [6] evaluates the performance of English teachers from China and foreign countries from the perspective of students majoring in English. Literature [7] proposes a diverse evaluation feedback system for English teachers in colleges, while literature [8] introduces a professional growth and evaluation system for college English teachers. Literature [9] discusses the possibility of applying a formative evaluation system to English teachers' classroom teaching. The second aspect concerns content research in classroom teaching quality, more precisely, classroom teaching quality evaluation systems. For example, literature [10] constructs a college English evaluation system and verifies it in practice; literature [11] introduces an ISO 9000 standard-based vocational English teaching quality evaluation system and literature [12] analyzes an English teaching evaluation system based on MI theory. Meanwhile, literature [13] studies multiple evaluation systems to assess the quality of college English classroom teaching; literature [14] conducts research on college English teaching quality evaluation systems, and literature [15] advocates a facet-diversified College English teaching quality evaluation system. Literature [16] studies the influences of improving evaluation systems upon the quality of college English teaching; literature [17] assesses English classroom teaching quality evaluation systems; literature [18] explores classroom teaching quality evaluation and its execution in comprehensive English courses, while literature [19] introduces a teaching quality evaluation and monitoring system for agricultural colleges and universities. The third aspect is about how to rate teaching quality grades after determining each index in the system. For example, literature [20] designs an optimized BP network based on a college English teaching quality evaluation model; literature [21] designs a PCA-LVQ neural network for teaching quality evaluation; literature [22] studies and realizes a BP neural network- based college classroom teaching quality evaluation system; and literature [23] applies the multilayer grey evaluation method to classroom teaching quality evaluation. In terms of research subjects, the above research includes common teacher self-evaluations, peer evaluations, administrative evaluations, expert evaluations, and student evaluations. In terms of evaluators, the evaluators involved are not inclusive enough to cover major different sources of subjects like teachers, students, and administrators. In terms of evaluation index selection, the same evaluation index system is adopted for different 
colleges and different disciplines by drawing upon an undergraduate teaching work level evaluation index system among general institutes of higher education, which is not rational. In terms of evaluation methods, the application of vague comprehensive evaluation methods will cause inconsistent evaluation results. The algorithms of the LVQ neural network and BP neural network, as an optimization method for local searching, aim at solving the global extremum for complex non-linear functions. Therefore, the algorithm may slip into the local extremum and lead to failure. For traditional BP neural network algorithms, there are shortcomings like a slowed convergence rate in learning, a tendency of slipping into local minimum and poor robustness, hence affecting prediction efficiency and accuracy. Because the ELM algorithm randomly assigns input weight matrix and hidden layer bias, enough hidden layer neurons are needed to reach required accuracy, while excessive hidden layer neurons will cause a tendency to overfit and increase the calculation amount.

To assess English teaching in university classrooms, a valid, accurate and feasible evaluation model is needed to avoid the problems that exist in previous evaluation systems and methods. This research, based on previous research results, studies classroom teaching quality evaluation systems and methods in the setting of classroom teaching of English as a foreign language (EFL) in China at university level. Combining current informationization backgrounds, the study re-defines the new classroom teaching quality evaluation index system for English teachers, and builds a PSOELM-based English teacher classroom teaching quality evaluation model.

\section{Basic Rationale of PSO-elm algorithm}

\subsection{Basic Rationale of PSO Algorithm}

All particles in solution space have an adaptive value and a speed that will determine their flying direction and distance. They will follow current optimal particles to search in solution space [24]. It is assumed that in D dimension search space, there are $\mathrm{m}$ particles; and in D dimension search space, there is swarm $x=\left(x_{1}, x_{2}, \ldots, x_{m}\right)$ composed of $m$ particles ; substitute $x$ into fitness function $f(x)$ to work out the fitness value of particles, Fitness ${ }_{i} ; x_{i}=\left(x_{i 1}, x_{i 2}, \ldots, x_{i D}\right)^{T}$ is a vector of its flying speed, expressed as $v_{i}=\left(v_{i 1}, v_{i 2}, \ldots, v_{i D}\right)^{T}$; the optimal location searched by $i$ particle is $p_{i}=\left(p_{i 1}, p_{i 2}, \ldots, p_{i D}\right)^{T}$; the optimal location searched by the whole particle swarm is $p_{\text {gbest }}=\left(p_{\text {gbest } 1}, p_{\text {gbest } 2}, \ldots, p_{\text {gbest }}\right)^{T}$. The speed of $i$ particle is updated to:

$$
v_{i d}^{k+1}=w v_{i d}^{k}+c_{1} r_{1}\left(p_{i d}^{k}-x_{i d}^{k}\right)+c_{2} r_{2}\left(p_{g b e s t}^{k}-x_{i d}^{k}\right)
$$

The position is updated to:

$$
x_{i d}^{k+1}=x_{i d}^{k}+v_{i d}^{k+1} \quad i=1,2, \mathrm{~L}, m ; d=1,2, \mathrm{~L}, D
$$

Where, $w$ is inertia weight, showing the trust of a particle on its current moving state, and inertia movement is conducted based on its own speed [25]. $c_{1}$ and $c_{2}$ are 
positive constants called accelerated factors, representing the weight of statistical accelerating items of pushing particles to $P_{\text {best }}$ and $g_{\text {best }}$ locations [26], $r_{1}$ and $r_{2}$ are two random numbers, the value range of which is $(0,1)$, so as to increase the randomness of the search.

\subsection{Rationale of ELM Algorithm}

Different from traditional neural networks, the hidden layer of the process neural network consists of operators that can complete temporal and spatial aggregation operations [27]. In addition, input process and weight are the functions related with time, which can reflect the spatial aggregation function and temporal accumulation effect of the time varying input signal, with the most representative one being the single-hidden layer feedforward neural network (SLFN). As one new type of SLFN, the ELM algorithm randomly produces the connection weight between input layer and hidden layer as well as the neural threshold value of the hidden layer. In the process of training, no adjustment is needed, and what we need to do is to set the number of neurons in the hidden layer. As a result, the only optimal solution will be obtained [28]. The topological structure is as shown in Fig.1.

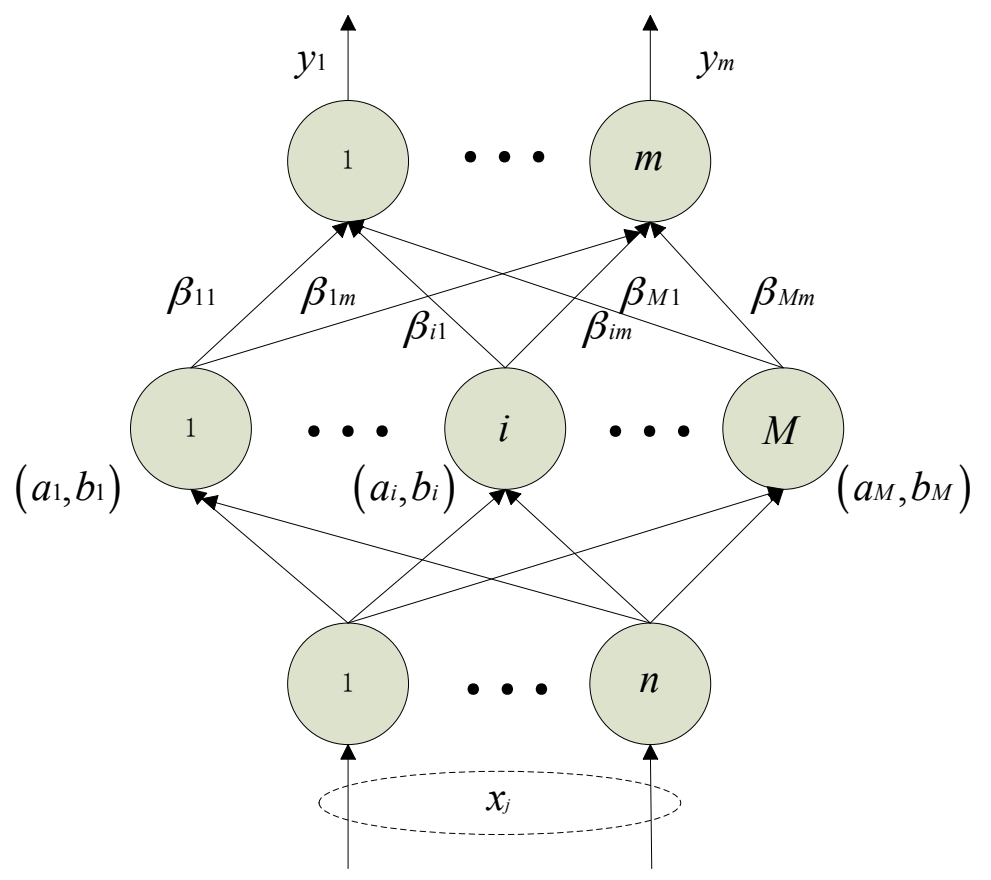

Fig. 1. SLFN structure

As shown in Fig. 1, if there are $N$ training samples $\left(x_{i}, t_{i}\right)$, where $x_{i}=\left(x_{i 1}, x_{i 2}, \ldots, x_{i D}\right)^{T}$ $\in R^{n}, t_{i}=\left(t_{i 1}, t_{i 2}, \ldots, t_{i D}\right)^{T} \in R^{m}$, then when there are $M(M \leq N)$ hidden nodes and the activation function is $g(x)$, the SLFN model can be expressed as: 


$$
\sum_{i=1}^{M} \beta_{i} g\left(a_{i} \cdot x_{j}+b_{i}\right)=O_{i, j}=1, \mathrm{~K}, N
$$

In Formula (1): to connect the input weight of the $i^{\text {th }}$ node in the hidden layer, $a_{i}=\left[a_{i 1}, a_{i 2}, \ldots, a_{i n}\right]^{T} ; b_{i}$ is the deviation of the $i^{\text {th }}$ node in the hidden layer; $\beta^{i}$ is the output weight of the node in the hidden layer, and $a_{i} * x_{j}$ represents the inner product of $a_{i}$ and $x_{j}$. The activation function $g(x)$ can be "Sigmoid," "Sine," or "RBF".

The learning goal of SLFN is to minimize the cost function $E(\omega)$, which represents the sum of squared errors between target output and expected output.

$$
E(\omega)=\sum_{i=1}^{N}\left\|O_{j}-t_{j}\right\|^{2}=0
$$

Namely there are $\beta_{i}, a_{i}, b_{i}$,

$$
\sum_{i=1}^{M} \beta_{i} g\left(a_{i} \cdot x_{j}+b_{i}\right)=t_{j}, j=1, \mathrm{~K}, N
$$

Formula (5) can be expressed through matrix:

$$
H \beta=T
$$

where,

$$
\begin{aligned}
& H\left(a_{1}, \mathrm{~K}, a_{M}, b_{1}, \mathrm{~K}, b_{M}, x_{1}, \mathrm{~K}, x_{M}\right)= \\
& {\left[\begin{array}{ccc}
g\left(a_{1} \cdot x_{1}+b_{1}\right) & \mathrm{L} & g\left(a_{M} \cdot x_{1}+b_{M}\right) \\
\mathrm{M} & \mathrm{L} & \mathrm{M} \\
g\left(a_{1} \cdot x_{N}+b_{1}\right) & \mathrm{L} & g\left(a_{M} \cdot x_{1}+b_{M}\right)
\end{array}\right]_{N \times M}} \\
& \beta=\left[\begin{array}{c}
\beta_{1}^{T} \\
\mathrm{M} \\
\beta_{M}^{T}
\end{array}\right]_{M \times m} \text { and } \quad T=\left[\begin{array}{c}
t_{1}^{T} \\
\mathrm{M} \\
t_{N}^{T}
\end{array}\right]_{N \times m}
\end{aligned}
$$

$H$ is the output matrix of the hidden layer; $\beta$ is the output weight; and $T$ is the expected output. Based on previous research, Huang et al. proposed the ELM algorithm for SLFN based on the following theorems, hence providing the theoretical foundation for the application of the ELM algorithm.

Theorem 1:

Assuming that there are $N$ random and different samples $\left(x_{i}, t_{i}\right)$, where $x_{i}=\left[x_{i}\right.$, $\left.x_{i 2}, \ldots, x_{i n}\right]^{T} \in R^{n}, t_{i}=\left[t_{i 1}, t_{i 2}, \ldots, t_{i m}\right]^{\mathrm{T}} \in R^{m}$, infinite and derivable activation functions between $N$ hidden layer nodes and any range $g: R \rightarrow R$, and values for SLFN within $a_{i} \in$ 
$R^{n}$ and $b_{i} \in R$ are randomly assigned, the formed hidden layer matrix $H$ is reversible, that is, there is an accurate solution to the equation set, and the cost function $E(\omega)=0$.

Theorem 2:

Assuming that there are $N$ random and different samples $\left(x_{i}, t_{i}\right)$, where random error $e>0$, and the infinite and derivable activation function within any range $g: R \rightarrow R$, there will always be one SLFN containing $M(M \leq N)$ hidden layer nodes, which will make the error $E(\omega) \leq e$ under the random assignment of $a_{i} \in R^{n}$ and $b_{i} \in R$.

From Theorems 1 and 2, it can be known that as long as there are enough nodes in the hidden layer, SLFN can approach any continuous function under the random assignment of input weight. Meanwhile, after confirming model training parameters, we can define a reversible hidden layer output matrix, so as to transform the SLFN training process into the issue of computing the least square solution for $H \beta=T$. The hidden layer output weight computation formula is:

$$
\hat{\beta}=H^{+} T
$$

Where $\mathrm{H}^{+}$stands for the Moore-Penrose of the output matrix in the hidden layer.

Based on the above, the ELM algorithm can be understood as: given a training set $\left\{\left(x_{i}, t_{i}\right) \mid x_{i} \in R^{n}, t_{i} \in R^{m}, i=1, \ldots N\right\}$, activation function $g(x)$ and hidden layer node number $M$.

(1) Randomly assign input weight $a_{i}$ and $b_{i}$ threshold values, both of which are within the range of $[-1,1]$;

(2) Compute the hidden layer output matrix $H$;

(3) Compute through Formula (9).

\subsection{PSO-ELM Algorithm}

Since ELM randomly assigns the input weight matrix and hidden layer bias, it can be seen from Formulas (3-6) that the output weight matrix is obtained by calculating the input weight matrix and hidden layer bias. The input weight matrix and hidden layer bias can also be 0 , that is, some hidden layer neurons are invalid. Therefore, in actual application, ELM needs a large number of hidden layer neurons to reach ideal accuracy, and besides, ELM has a poor reaction capacity against the samples that have not appeared in the training set, i.e., the generalization ability is poor. As for problems in the ELM algorithm, this paper proposes one kind of PSO-ELM algorithm which combines the PSO and ELM network, i.e., utilizing PSO optimization to choose input weight and hidden layer bias for ELM so as to obtain an optimal network.

This paper uses PSO to optimize the input weight and threshold of ELM, and uses the input weight and threshold of ELM as particles for the PSO algorithm and rootmean-square error (RMSE) of training samples as a fitness function for the PSO algorithm. The smaller the fitness, the more accurate the prediction, and it is the same case with input weight and threshold. Compared with ELM, this model does not need to set up the number of hidden layer neurons, initial weight and bias, so it enjoys better stability and generalization. In training, PSO is utilized to locate the optimal output 
weight according to norms, so as to generate the optimal output range and ultimately reduce the complexity of model training.

The steps for the PSO-ELM algorithm are as follows:

1. Preset learning sample, which includes input vector and expected output vector;

2. Determine the neuron numbers and functions selected to be activated of the input layer, hidden layer, and output layer, and build the PSO-ELM neural network topology;

3. Generate the population, initialize the particle location and speed. Set up the optimizing scope of particle speed and location according to the weight and threshold range; choose suitable parameters, suitable learning factors $c_{1}$ and $c_{2}$, inertia weight $w$, particle dimension $D$, and maximal iteration time $T$ as well as population size $m$;

4. Determine the fitness function, calculate the fitness value for each particle, and obtain the individual extremum of each particle and the global extremum;

5. Through comparison, constantly update the speed and location of particles;

6. Judge whether the maximal iteration time or minimal error is reached. If reached, stop iteration, and at this moment the group extremum is the PSO-ELM input weight and hidden layer neuron threshold. If not reached, turn to step 4 to continue iteration;

7. For the corresponding input weight and hidden layer neuron threshold of optimal fitness obtained in step 4, use Formula (9) to calculate the output weight matrix.

\section{Building classroom teaching quality evaluation index system for English teachers}

As an important part of classroom teaching studies, the quality evaluation of classroom teaching combines teaching approaches and a series of teaching methods based on formative evaluation thoughts. This method aims at assessing the performance of teachers through a non-stop evaluation of their performance in class. The tenet of college English classroom evaluation lies in improving the quality of teaching and student learning through effective teacher-student information feedback.

Establishing an evaluation index system is the key to the quality evaluation of an English teacher's classroom teaching. Based on the four basic principles of objectiveness, scientificness, operability and elementariness, an index system for an English teacher's classroom teaching quality evaluation has been established. There are many factors affecting teaching quality, so if all influencing factors are included in the system, the evaluation work will be excessively complex and difficult. Hence, the evaluation index system aims at assessing the key points and highlighting the focus. The process is as follows: firstly, collect information through expert consultation, teacher reviews and student questionnaires; then use factor analysis and cluster analysis methods to screen out comprehensive evaluation factors, which are summed up as teaching attitude, teaching process, teaching content, teaching method, and teaching approach. Based on the five evaluation factors and relevant literature, 25 statements and evaluations about a college English teacher's classroom teaching quality evalua- 
tion index are obtained, and furthermore 25 initial indexes are designed. Later, collect comments from experienced evaluation theory researchers, education administrators, and teachers so as to modify the expression and connotation of indexes and ultimately further optimize the evaluation indexes. Fifteen indexes are selected out of the 25 initial indexes to measure the five dimensions of a college English teacher's classroom teaching quality as shown in Table 1.

Table 1. Quality evaluation index system for EFL classroom teaching

\begin{tabular}{|c|c|}
\hline Primary index & Secondary index \\
\hline \multirow{2}{*}{ Teaching attitude } & Dress appropriately and show enthusiasm $\left(x_{1}\right)$ \\
\hline & Standard pronunciation and sonorous sound $\left(x_{2}\right)$ \\
\hline \multirow{4}{*}{ Teaching content } & $\begin{array}{l}\text { Match teaching content with teaching time: balancing teaching depth and information } \\
\text { amount with teaching time }\left(x_{3}\right)\end{array}$ \\
\hline & $\begin{array}{l}\text { Familiar with teaching content, accurate and clear explanation of problems with high- } \\
\text { lighted key points and suitable examples }\left(x_{4}\right)\end{array}$ \\
\hline & $\begin{array}{l}\text { Effective use of various teaching approaches, with a combination of blackboard writ- } \\
\text { ing and multimedia }\left(x_{5}\right)\end{array}$ \\
\hline & $\begin{array}{l}\text { Pay attention to interaction and student participation, with clear, flexible and illuminat- } \\
\text { ing teaching methods }\left(x_{6}\right)\end{array}$ \\
\hline \multirow{3}{*}{$\begin{array}{l}\text { Teaching method } \\
\text { and approach }\end{array}$} & $\begin{array}{l}\text { Moderate speed, with suitable pauses, standard English expressions, fluency, logic, } \\
\text { suitable information amount in multimedia courses; course-ware has proper pictures, } \\
\text { refined captions and high quality }\left(x_{7}\right)\end{array}$ \\
\hline & Clarify teaching goals and enable students to reach the goals after class $\left(x_{8}\right)$ \\
\hline & Choice of topics that can stimulate student participation $\left(x_{9}\right)$ \\
\hline \multirow{3}{*}{ Teaching effect } & Students made quick progress in learning $\left(x_{10}\right)$ \\
\hline & $\begin{array}{l}\text { Thorough teaching analysis; rich teaching content that can reflect academic progress or } \\
\text { practical use }\left(x_{11}\right)\end{array}$ \\
\hline & Clear and distinct teaching goals $\left(x_{12}\right)$ \\
\hline \multirow{3}{*}{ Teaching design } & $\begin{array}{l}\text { Accurately grasp key and difficult points and take enough measures to solve problems } \\
\left(x_{13}\right)\end{array}$ \\
\hline & $\begin{array}{l}\text { Special design of teaching process, reasonable classroom teaching organization, effec- } \\
\text { tive teaching methods, and suitable application of teaching approaches }\left(x_{14}\right)\end{array}$ \\
\hline & Accurate and concise literal expressions with clear explanations $\left(x_{15}\right)$ \\
\hline
\end{tabular}

As shown in Table 1, the teaching attitude dimension consists of the two indexes $\left(x_{1}\right)$ and $\left(x_{2}\right)$, the teaching content dimension consists of four indexes ranging from $\left(x_{3}\right)$ to $\left(x_{6}\right)$, the teaching method and approach dimension consists of three indexes ranging from $\left(x_{7}\right)$ to $\left(x_{9}\right)$, the teaching effect dimension consists of three indexes from $\left(x_{10}\right)$ to $\left(x_{12}\right)$, and the teaching design dimension consists of three indexes ranging from $\left(x_{13}\right)$ to $\left(x_{15}\right)$.

The evaluation subject of this model is students. Students will give scores $S$ $(0<S<99)$ to English teachers according to the above 15 indexes. Evaluation results are divided into five grades, namely A (excellent), B (good), C (fair), D (relatively poor) and $\mathrm{E}$ (poor).

In evaluating the classroom teaching quality of college English teachers, there are 15 specific evaluation indexes with evaluation results divided into five grades. 


\section{Building PSO-elm based evaluation model of classroom teaching quality for English teachers}

The process of building the PSO-ELM English teaching classroom evaluation model entails creating the PSO-ELM neural network topology, that is, determining the input layer neuron number, output layer neuron number, hidden layer neuron number, activation of the function, and network learning algorithm.

\subsection{Input layer neuron number}

The indexes of students' evaluation of English teachers include 5 primary indexes and 15 secondary indexes, while the secondary evaluation indexes are taken as the input of the input layer of the neural network, so the PSO-ELM input layer neuron number shall be 15 .

\subsection{Output layer neuron number}

There is only one result of the student evaluation, so the network output layer shall only have one output neuron.

\subsection{Hidden layer neuron}

The number of hidden layer neurons can be determined through some empirical formulas with an explicit hidden layer neuron number or through the generalization performance of three excitation functions of "Sigmoid," "Sine," and "RBF," This paper firstly determines the general scope of the hidden layer neurons according to empirical formulas, then locates the accuracy of each hidden layer neuron number, and finally chooses the hidden layer neuron number with the largest accuracy as the optimal hidden layer neuron number.

\subsection{Determination of excitation function}

Given that the expected output value of the evaluation result will fall into the range after normalization processing in the training data sample set, all the activation functions on the output layer units adopt "Sigmoid," the form of which is as follows:

$$
g(x)=\frac{1}{1+e^{-x}}
$$

\subsection{Network learning algorithm}

The network learning algorithm adopts the PSO-ELM algorithm. 


\section{Evaluation model case analysis}

\section{$5.1 \quad$ Experiment environment}

Hardware: CPU:Intel(R) Core(TM) 3.60GHz; internal storage: $8 \mathrm{G}$

Software: Matlab2014b

\subsection{Data source and processing}

The classroom teaching evaluation system was used in 2015 to evaluate teaching performance of English teachers from Department of Foreign Languages, Northwest A\&F University, China.As data for the experiment, 157 sets of data were chosen from the 2015 teacher evaluation database. Among them, training samples made up the first 132 sets, and testing samples the following 25 sets, with selected results as shown in Table 2. to obtain a classroom teaching quality evaluation for English teachers. If the results are consistent with the testing target, the judgment is correct, otherwise it is incorrect Normalization processing was conducted for the 15-index data input, with $\mathrm{A}, \mathrm{B}, \mathrm{C}, \mathrm{D}, \mathrm{E}$ in the output results corresponding to $1,2,3,4,5$.

Table 2. Selection Of Training Samples And Testing Samples

\begin{tabular}{|c|c|c|c|}
\hline Evaluation grade & Total number of samples & Training sample number & Testing sample number \\
\hline 1 & 7 & 5 & 2 \\
\hline 2 & 28 & 23 & 5 \\
\hline 3 & 103 & 89 & 14 \\
\hline 4 & 13 & 10 & 3 \\
\hline 5 & 6 & 5 & 1 \\
\hline Sum & 157 & 132 & 25 \\
\hline
\end{tabular}

\subsection{Experiment results and analysis}

Given the experiment data scale and experiment results of several times, the main parameters for PSO are set as follows: maximum number of iterations $T=300$, population size $m=100$, inertia weight $w=0.8$, learning factor $c_{1}=c_{2}=2.02$, dimension number of particles $D=M \cdot(n+1)$, where $M$ refers to the number of hidden layer neurons and $n$ refers to the number of input layer neurons. The fitness function is the error number of training samples. Firstly, the PSO-ELM classifier model is used for simulation, with a fitness curve as shown in Fig.2. 


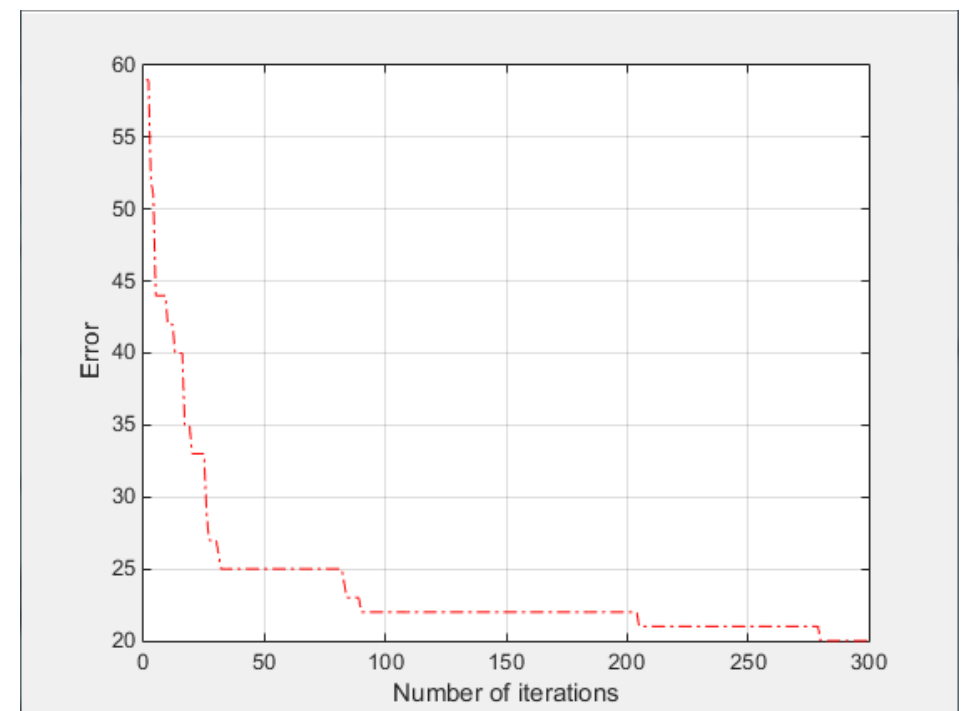

Fig. 2. Fitness curve

From Fig.2, the errors (error number of training samples) decrease with an increase of iteration times. When iteration times reach a certain value, they slow down on the error decrease. When the iteration times reach the maximal iteration time 300 , the errors reach their minimal value.

To compare and analyze PSO-ELM and ELM, this paper uses the ELM model for classification. The hidden layer neuron number has a great influence upon ELM. When training is carried out 10 times using PSO-ELM and ELM when the hidden layer neuron number is $10,20,30,40,50,60,70,80,90,100$, the average accuracy of the training sample and testing sample changes with the hidden layer neuron numbers as shown in Figs. 3 and 4.

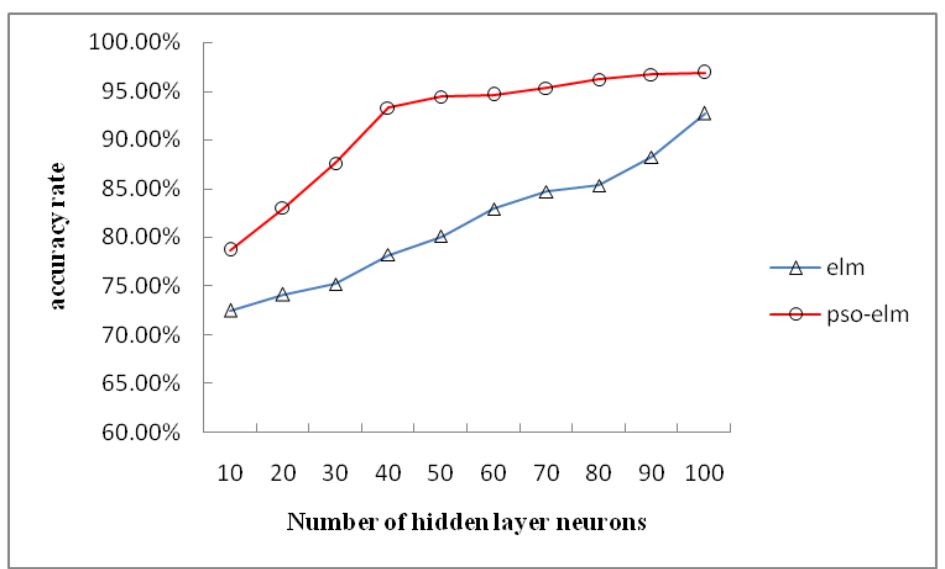

Fig. 3. Curve between training sample accuracy and hidden layer neuron number 


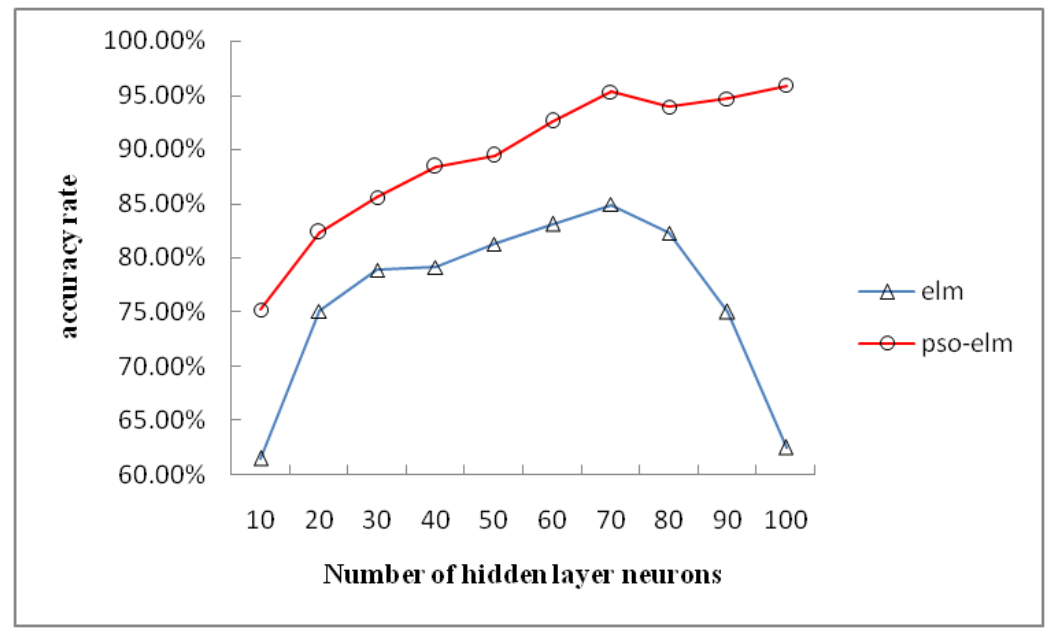

Fig. 4. Curve between testing sample accuracy and hidden layer neuron number

Fig3 and 4, show that the training accuracy and testing accuracy of ELM are more sensitive to hidden layer neuron numbers. The training accuracy rapidly decreases with the increase of hidden layer neuron numbers. When the hidden layer neuron number equals the training sample number, training accuracy can reach zero error. The testing accuracy is relatively high and stable when the hidden layer neuron number is small. Once the number of hidden layer neurons approaches the training sample number, the testing sample error increases sharply and produces overfitting. For PSOELM, after PSO, the training sample accuracy is obviously higher than for the ELM model, and the number of hidden layer neurons sees no dramatic change, thus being sound and stable. The testing sample accuracy also sees an improvement over the ELM model, and when the hidden layer neuron number is small (less than 85), the testing error is relatively stable. To maximize accuracy, the hidden layer neuron number is set to be 70 .

The PSO-ELM and ELM training set classification results are shown in Fig.5, and the testing set classification results are shown in Fig.6.

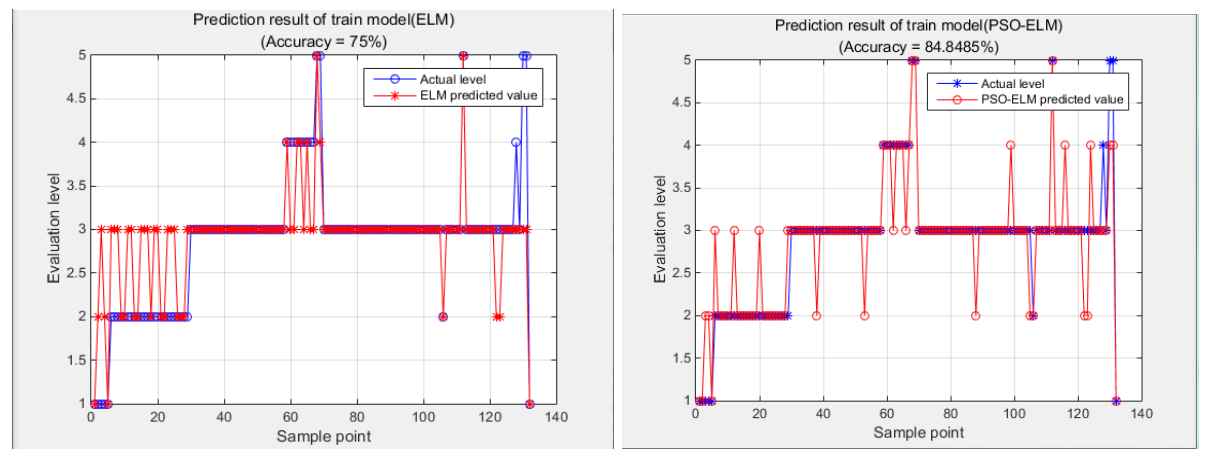

Fig. 5. Training set classification results 

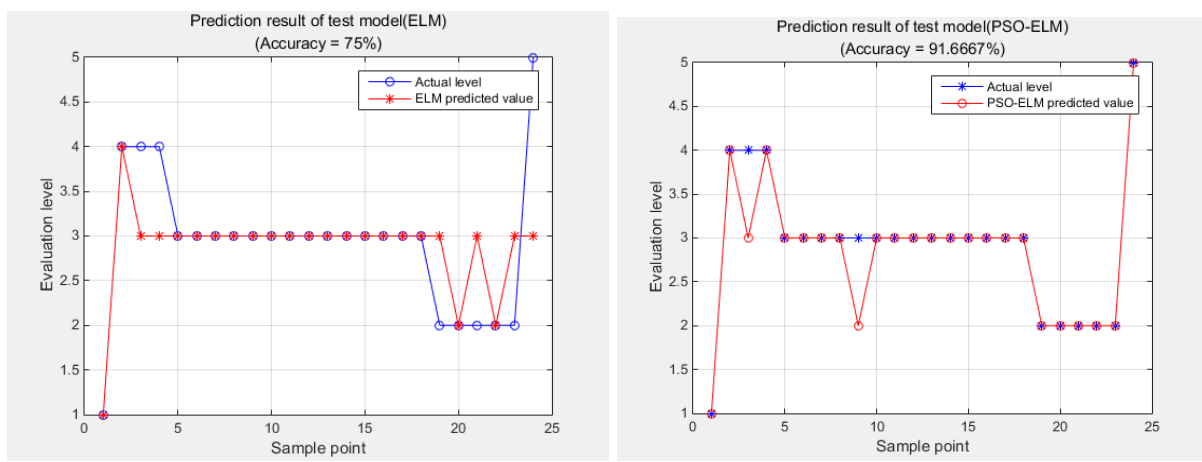

Fig. 6. Testing set classification results

From Figs.5 and.6, it can be clearly seen that the PSO-ELM evaluation judgment accuracy is higher than the ELM's. The ELM classification model operates less than 1s. Although the operation time of the ELM classification model is shorter than that of the PSO-ELM classification model, it is not outperformed in terms of classification accuracy. The accuracy of the PSO-ELM classification model is higher, so the model displays a better classification and anti-disturbance ability as well as a stronger generalization ability than the ELM classification model. Therefore, adopting the PSOELM classification model to evaluate the classroom teaching performance of English teachers clearly yields more accurate results and is more reasonable.

\section{Conclusion}

To improve the effectiveness of classroom teaching of English as a foreign language (EFL) in China at university level, this study designed a quality evaluation index system and proposed a PSO-ELM quality evaluation model for college English classroom teaching, based on analyzing the defects of existing models, such as complex structure, slow learning speed, and poor generalization. Experiment results showed that:

1. This model displayed remarkable training accuracy and stability as well as strong generalization ability.

2. The PSO-ELM model overcame the disadvantages of the existing ELM algorithm, such as poor generalization, tendency of slipping into local minimum, and poor searching ability.

3. The PSO-ELM algorithm chose the optimal input weight matrix and hidden layer bias, thus improving English teaching and learning.

4. The PSO-ELM algorithm is more suitable for the classroom teaching quality evaluation of English teachers than the ELM algorithm, hence providing a new method for evaluating the classroom teaching quality of English teachers.

With a lot of importance being attached to English teaching in today's university classrooms, this study is supposed to shed new light on English teaching evaluation, 
and on teachers' self-reflective teaching in terms of teacher attitude, teaching content, design and methodology, and teaching effect.

\section{$7 \quad$ References}

[1] Lu, L.H. (2011). A Descriptive Study of English Teachers' Understanding of the Standards for the College Teaching Evaluation. Open Education Research, 17(4): 79-83. Doi: 10.3969/j.issn.1007-2179.2011.04.011.

[2] Cui, H.Y., Feng, X.R. (2012). Constructing the self-evaluation mechanism of teachers, Promoting professional development of English teachers in Higher Vocational Colleges. Journal of Changsha Social Work College, 1: 126-128. Doi: 10.3969/j.issn.16715136.2012.01.036.

[3] Wu, Y., Tang, J.L. (2012). Impact of Integrating an Automated Assessment Tool into English Writing on University Teachers. Computer-Assisted Foreign Language Education in China, 4: 3-10. Doi: 10.3969/j.issn.1001-5795.2012.04.001.

[4] Shi, Q.Y. (2007). Assessment of EFL Teacher Behavior in College English Class. Shanxi University.

[5] Li, T. (2006). Thinking on the Present Evaluation System for English Teachers of Senior Schools. Huazhong Normal University. Doi: 10.7666/d.y875974.

[6] Tian, Q.X. (2013). A study on the teaching evaluation of English major students to Chinese and foreign English teachers. Education Exploration, 2: 74-75. Doi: 10.3969/j.issn.1002-0845.2013.02.027.

[7] Zhang, J.P., Liu, P.J. (2015). Feedback evaluation and promotion of professional development -- the construction of College English teachers' diversity evaluation feedback system. Crazy English Teachers, 1: 120-123. Doi: 10.3969/j.issn.1006-2831.2015.01.032.

[8] Shen, H.W., Jiang, H.X. (2014). A study on the construction of College English teachers' professional development and evaluation system. Journal of Hubei Correspondence University, 18: 25-26. Doi: 10.3969/j.issn.1671-5918.2014.18-013.

[9] Liu, T.T. (2011). On the Application of the Developing Teacher Evaluation System in the Evaluation of English Teachers. Journal of Hubei Correspondence University, 24(1): 3031. Doi: 10.3969/j.issn.1671-5918.2011.01.015.

[10] Liu, H.M. (2010). Construction and Practice of College English Evaluation System. Heilongjiang Education (Higher Educational Research and Evaluation), 7: 23-24. Doi: 10.3969/j.issn.1002-4107.2010.07.010.

[11] Gao, C. (2015). preliminary study on the evaluation system of Higher Vocational English teaching quality based on ISO9000 standard. China Adult Education, 383(22): 176-178.

[12] Tan, X.S. (2016). MI theory and the construction of the evaluation system of English Teaching. Journal of Shandong Agricultural Administrators' College, 33(6): 7-8. Doi: 10.3969/j.issn.1008-7540.2016.06.004.

[13] Zhao, Y.J. (2012). A Study on the Construction of Multi-Evaluation System of Teaching Quality for College English Course: A Case Study of Chongqing Science and Technology University. Journal of Sichuan International Studies University, 28(6): 169-173. Doi: 10.3969/j.issn.1674-6414.2012.06.038.

[14] Ruan, J., Zhao, Z.M. (2015). Research on the evaluation system of College English teaching quality. Journal of Heilongjiang College of Education, 6: 141-142. Doi: 10.3969/j.issn.1001-7836.2015.06.065.

[15] Zhou, B.G. (2011). On the Diversification of CE Teaching Quality Evaluation System. Scientific Research Publishing, Capital University of Economics and Business, Hohai 
University, Jiangxi University of Finance and Economics, Shanghai Second Polytechnic University, 2011 International Conference on Education Science and Management Engineering, 2697-2699.

[16] Wu, X.F. (2005). Improving the evaluation system and improving the quality of College English Teaching. China Adult Education, 1: 68-69. Doi: 10.3969/j.issn.10046577.2005.01.040.

[17] Zeng, X.Y. (2008). On the evaluation system of English classroom teaching quality. Journal of teaching and management, 6: 60-62. Doi: 10.3969/j.issn.1004-5872.2008.06.028.

[18] Wang, H. (2002). Evaluation of classroom teaching quality and its implementation in Integrated English class. Journal of Shaanxi Normal University (Philosophy and Social Sciences Edition), 31: 32-34.

[19] Zhang, S.J., Xu, H., Chen, L.J. (2011). Construction of teaching quality evaluation and monitoring system in agricultural colleges and Universities- Taking English graded teaching as an example," Agricultural Archaeology, 3: 279-281.

[20] Ma, H. (2014). A model of evaluating English teaching Quality Based on the BP Neural network. Information Engineering Research Institute, USA, 2014 4th International Conference on Applied Social Science, 54: 17-21.

[21] Hu, S., Gu, Y., Qu, W.W. (2015). Teaching Quality Assessment Model Based on PCALVQ Neural Network. Henan Science, 7: 1247-1252.

[22] Cai, J.J. (2009). Research and Solution of University Classroom Teaching Quality Evaluation System Based on Bpnn. Zhejiang University of Technology. Doi: 10.7666/d.y1530164.

[23] Deng, Y.M. (2004). Application of multi-level grey evaluation method in the evaluation of classroom teaching quality," Science \& Technology Progress and Policy, 21(12): 143-144. Doi: 10.3969/j.issn.1001-7348.2004.12.056.

[24] Zhang, F.F., Wang, J.J., Zhang, Y. (2015). Review of Particle Swarm Optimization Process in Facilities Location Problem. Logistics Technology, 7: 58-61, 78. Doi: 10.3969/j.issn.1005-152X.2015.04.021.

[25] Song, L.L., Zhu, C., Sun, W.L. (2015). Optimization and Research of PID Controller Based on Particle Swarm Optimization. Journal of Changji University, 6: 76-80. Doi: 10.3969/j.issn.1006-9348.2012.05.056.

[26] Wang, J., Bi, H.Y. (2013). A New Extreme Learning Machine Optimized by PSO. Journal of Zhengzhou University (Natural Science Edition), 45(1): 100-104. Doi: 10.3969/j.issn.1671-6841.2013.01.024.

[27] Quiñonez, Y., Tostado, I., Burgueño, C. (2015). Aplicación de técnicasevolutivas y visiónporcomputadora para navegaciónautónoma de robots utilizando un TurtleBot 2. RISTI-Revistalbérica de Sistemas e Tecnologias de Informação, SPE3: 93-105.. https://doi.org/10.17013/risti.e3.93-105

[28] Cui, D.W. (2013). Application of extreme learning machine to total phosphorus and total nitrogen forecast in lakes and reservoirs. Water Resources Protection, 7: 61-66. Doi: 10.3969/j.issn.10046933.2013.02.013.

[29] Li, X.L., Zhou, Q., Zhu, J., Li, L., Jia, F.Y., Chen, J. (2016). Application of GIS and Improved PSO Algorithm in Site Selection of Transformer Substation. Review of Computer Engineering Studies, 3(2): 39-42. Doi: 10.18280/rces.030203.

[30] Lin, T., Wu, P., Gao, F.M., Yu, Y., Wang, L.H. (2015). Study on SVM temperature compensation of liquid ammonia volumetric flowmeter based on variable weight PSO. International Journal of Heat and Technology, 33(2): 151-156. Doi: 10.18280/ijht.330224. https://doi.org/10.18280/ijht.330224 


\section{Authors}

Baojian Wang, with research focus on theories \& practices of teaching English as a foreign language and translation, is working for Department of Foreign Languages, Northwest A\&F University, 712100, Yangling, Shaanxi Province, China (Email: wang.baojian@163.com).

Jing Wang, (corresponding author), is with Northwest A\&F University, Yangling, Shaanxi Province, TX 712100, China. She is now with the Department of Foreign Languages, Northwest A\&F University, Yangling, PRC. (Corresponding author Email: jingwang@nwsuaf.edu.cn). Her study focuses on English feminism literature and TEFL.

Guoqiang Hu, born in Shaanxi, received the B.E degree from Nanchang University in 2005.After graduation, he has been engaged in the work of computer network. He received M.E degree the Institute of Information Engineering (Northwest Agriculture \& Forestry University) in 2013, his research direction is intelligent network and machine learning (Email: hgq@nwsuaf. edu.cn).

Article submitted 16 February 2017. Published as resubmitted by the authors 20 March 2017. 